07

\title{
Люминесцентные свойства выращенных на InP слоев GalnAsP с градиентом состава по толщине
}

\author{
(ㄷ Г.С. Гагис ${ }^{1,2}$, А.С. Власов ${ }^{1}$, Р.В. Левин ${ }^{1}$, А.Е. Маричев ${ }^{1}$, М.П. Щеглов ${ }^{1}$, Т.Б. Попова ${ }^{1}$, Б.Я. Бер ${ }^{1}$, \\ Д.Ю. Казанцев ${ }^{1}$, Д.В. Чистяков ${ }^{3}$, В.И. Кучинский ${ }^{1,2}$, В.И. Васильев ${ }^{1,2}$ \\ ${ }^{1}$ Физико-технический институт им. А.Ф. Иофффе РАН, Санкт-Петербург, Россия \\ ${ }^{2}$ Санкт-Петербургский государственный электротехнический университет „ЛЭТИ“, Санкт-Петербург, Россия \\ ${ }^{3}$ Санкт-Петербургский национальный исследовательский университет информационных технологий, механики и оптики \\ (Университет ИТМО), Санкт-Петербург, Россия \\ E-mail: galina.gagis@gmail.com
}

Поступило в Редакцию 28 июня 2019г.

В окончательной редакции 28 июня 2019 r.

Принято к публикации 1 июля 2019 г.

Исследованы люминесцентные свойства при 77 и $300 \mathrm{~K}$ эпитаксиальных слоев $\mathrm{Ga}_{1-x} \operatorname{In}_{x} \mathrm{As}_{y} \mathrm{P}_{1-y}$, имеющих градиент содержания элементов пятой группы $\Delta y$ до 0.08 по всей толщине (около $1 \mu \mathrm{m}$ ). У слоев $\mathrm{Ga}_{1-x} \operatorname{In}_{x} \mathrm{As}_{y} \mathrm{P}_{1-y}$ с высокими $\Delta y$ спектры фотолюминесценции были уширены. У слоев GaInAsP низкого кристаллического совершенства фотолюминесценция либо отсутствовала, либо проявляла себя так, как это характерно для переходов с участием примесных уровней.

Ключевые слова: фотолюминесценция, твердые растворы, гетероструктуры, фотоэлектрические преобразователи.

DOI: 10.21883/PJTF.2019.20.48388.17954

Для активных областей фотоэлектрических преобра-

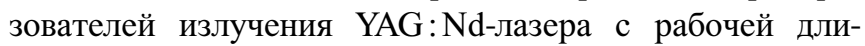
ной волны $1064 \mathrm{~nm}$, согласно [1], подходящими материалами являются твердые растворы $\mathrm{Ga}_{1-x} \mathrm{In}_{x} \mathrm{As}_{y} \mathrm{P}_{1-y}$ с составами $x=0.8-0.85, y=0.25-0.45$. Они обладают прямой структурой энергетических зон и могут быть изготовлены на подложках InP. Ранее нами сообщалось об исследовании подобных эпитаксиальных слоев $\mathrm{Ga}_{1-x} \mathrm{In}_{x} \mathrm{As}_{y} \mathrm{P}_{1-y}$, выращенных на подложках $\operatorname{InP}(001)$ методом газофазной эпитаксии из металлоорганических соединений при давлении $0.1 \mathrm{bar}$ и температуре $600^{\circ} \mathrm{C}[2,3]$. Составы исследованных в [2,3] образцов были измерены методом рентгеновского микроанализа на установке „Сamebax“ фирмы Сатеса и находились в пределах $x=0.77-0.87$, $y=0.07-0.42$. Следует отметить, что в процессе осаждения каждого эпитаксиального слоя GaInAsP, длившегося $60 \mathrm{~min}$, температура, давление и состав газовой смеси поддерживались постоянными. Тем не менее глубинное профилирование состава структур, проведенное с использованием вторично-ионной масс-спектрометрии (ВИМС) на ВИМС-микрозонде CAMECA IMS-7f, выявило существенное изменение содержания элементов пятой группы $\Delta y$ практически на протяженности всего слоя GaInAsP, толщины слоев GaInAsP составляли 0.6-0.9 $\mu \mathrm{m}$. О возможных причинах этого явления мы сообщали в [2,3], где также приводили основные результаты исследований полученных образцов методами рентгеновской дифрактометрии и ВИМС. Целью настоящей работы является анализ фотолюминесценции (ФЛ) образцов, полученных в [2,3], с учетом неоднородности их состава по толщине. Известно, что люминесцентные характеристики полупроводниковых структур связаны со степенью их кристаллического совершенства, которую мы оценивали по совокупности данных исследований ВИМС и рентгеновской дифрактометрии, а также по результатам исследований самой ФЛ.

Исследования с помощью рентгеновской дифрактометрии проводились на базе трехкристального рентгеновского дифрактометра „ДРОН-2“ с использованием симметричных рефлексов типа (004) в $\mathrm{Cu} K_{\alpha 1}$-излучении. В том случае, если пик отражения от слоя GaInAsP различался при использовании трехкристальной схемы (выполнялось для образцов № 3-5), в режиме $\theta / 2 \theta$ записывались зависимости интенсивности отражений рентгеновского луча от угла его падения $\theta$ - кривые дифракционного отражения (КДО). В данном случае углу $\theta$ можно сопоставить величину $(\Delta a / a)_{\perp}=\left(a_{\mathrm{GaInAsP} \perp}-a_{\mathrm{InP} \perp}\right) / a_{\mathrm{InP} \perp}, \quad$ которая характеризует различие параметров решетки слоя GaInAsP и подложки $\operatorname{InP}\left(a_{\mathrm{InP} \perp}\right.$ и $a_{\mathrm{GaInAsP} \perp}-$ параметры решетки подложки InP и слоя GaInAsP по направлению [001]). Поскольку слои GaInAsP в нашем случае неоднородны по составу и имеют целый спектр значений $(\Delta a / a)_{\perp}$, для характеристики образцов мы используем среднее значение $(\Delta a / a)_{\perp}^{M}$, определенное по центру тяжести пика отражения от GaInAsP. Мы полагаем, что чем больше $\left|(\Delta a / a)_{\perp}^{M}\right|$, тем ниже степень кристаллического совершенства. Кристаллическое совершенство образцов № 1 и 2, упомянутых в наших работах $[2,3]$, мы оцениваем как низкое. Поскольку при исследованиях методом рентгеновской дифрактометрии 


\section{3}

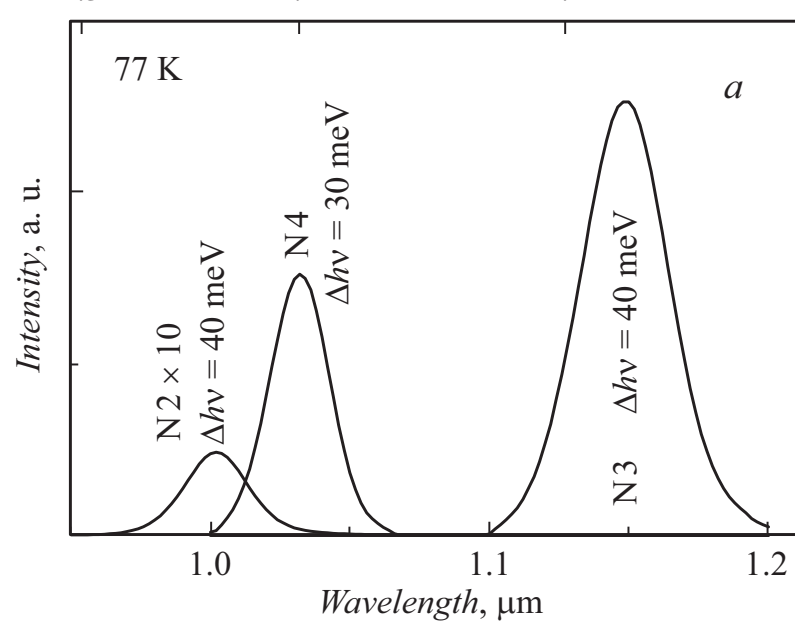

1.1
Energy, eV

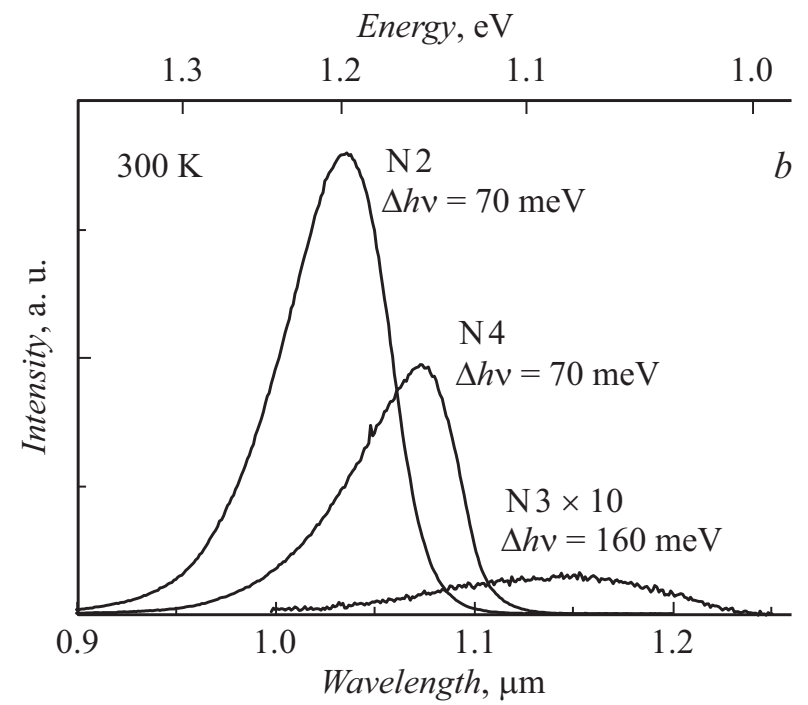

Pис. 1. Спектры ФЛ для образцов № $2-4$ при $77(a)$ и $300 \mathrm{~K}(b)$. Для кривых с пометкой $\times 10$ на диаграмме представлен сигнал, увеличенный в 10 раз.
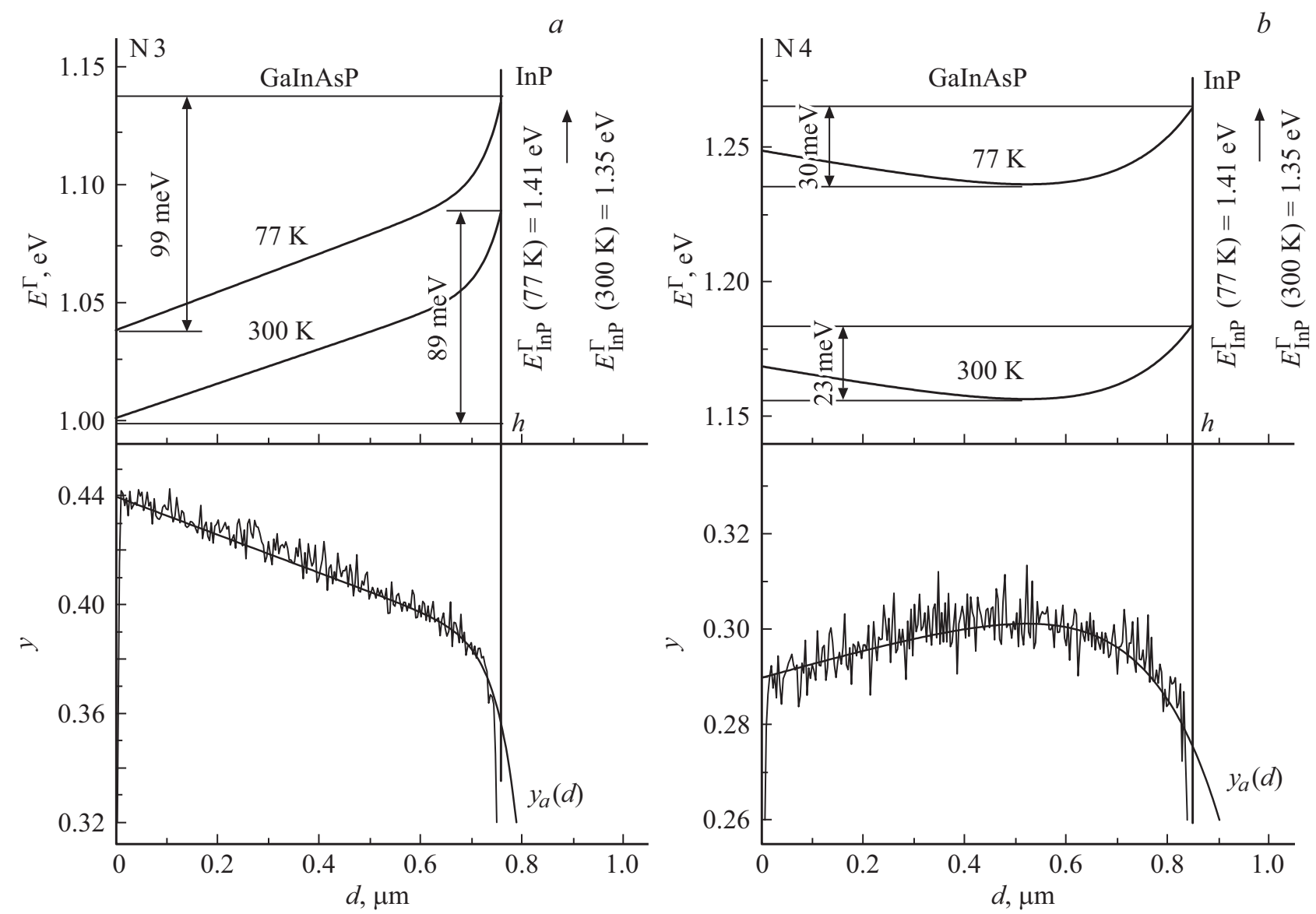

Рис. 2. Полученный методом ВИМС профиль содержания мышьяка $y$ и рассчитанный по составу профиль $E^{\Gamma}$ эпитаксиального слоя $\mathrm{Ga}_{1-x} \mathrm{In}_{x} \mathrm{As}_{y} \mathrm{P}_{1-y}$ для образцов № $3(a)$ и $4(b)$. Значение $d=0$ соответствует поверхности образца, $h-$ положение гетерограницы между слоем $\mathrm{Ga}_{1-x} \mathrm{In}_{x} \mathrm{As}_{y} \mathrm{P}_{1-y}$ и InP.

пики отражения от слоев GaInAsP не были различимы при использовании трехкристальной схемы, величина $(\Delta a / a)_{\perp}^{M}$ для них оценивалась с использованием двухкристальной схемы, и для образца № 1 оценка дает $(\Delta a / a)_{\perp}^{M}=-1.3 \cdot 10^{-2}$, а для образца № $2-$ $(\Delta a / a)_{\perp}^{M}=-7 \cdot 10^{-3}$. Образец № 5 исследовался с 
использованием трехкристальной схемы, имел широкий пик отражения от слоя, соответствующий диапазону рассогласований $-6 \cdot 10^{-3}<(\Delta a / a)_{\perp}<-1.1 \cdot 10^{-2}$, $(\Delta a / a)_{\perp}^{M}=-9 \cdot 10^{-3}$.

Также при оценке кристаллического совершенства мы рассматривали величину размытия гетерограницы $\Delta h$, определенную методом ВИМС по критерию 16\%-84\% по содержанию индия $x$. У образцов № 1 и $5 \Delta h=30 \mathrm{~nm}$, у образцов № 2-4 $\Delta h=15-20 \mathrm{~nm}$. Более высокие значения $\Delta h$ мы связываем с более низким кристаллическим совершенством.

Данные ФЛ также выступают критерием оценки степени кристаллического совершенства. ФЛ у образцов № 1 и 5 не наблюдалась, а для образцов № 2-4 имела различный характер (рис. 1).

Поведение спектра ФЛ образца № 2 характерно для примесных уровней: при $77 \mathrm{~K}$ он имеет интенсивность на порядок ниже, чем у образцов № 3, 4, а при комнатной температуре - сравнимую с интенсивностью ФЛ образцов № 3, 4. Это может свидетельствовать о большом количестве дефектов, которые препятствуют захвату носителей на поверхностные состояния. На большое количество дефектов у образца № 2 указывают и данные рентгеновской дифрактометрии: это крайне низкая интенсивность пика отражения от слоя, сильное рассогласование $(\Delta a / a)_{\perp}^{M}=-7 \cdot 10^{-3}$.

Для образцов № 3 и 4 мы связываем вид спектров ФЛ с градиентом состава, поскольку от состава зависит величина прямого энергетического зазора $E^{\Gamma}$, и она соответственно будет изменяться по толщине эпитаксиального слоя. Определенные методом ВИМС профили содержания мышьяка $y$ по толщине $d$ слоев $\mathrm{Ga}_{1-x} \operatorname{In}_{x} \mathrm{As}_{y} \mathrm{P}_{1-y}$ для образцов № 3 и 4 показаны на рис. 2. На КДО образца № 3 спектр отражений от слоя GaInAsP соответствовал изменениям величины $(\Delta a / a)_{\perp}$ в пределах $(0-+6) \cdot 10^{-3}$, что согласуется с наличием большого градиента состава: $\Delta y=0.08$. Для образца № 4 пик отражений от слоя на КДО соответствовал рассогласованиям $-5 \cdot 10^{-3}<(\Delta a / a)_{\perp}<-3 \cdot 10^{-3}$, а средняя величина $(\Delta a / a)_{\perp}^{M}=-4 \cdot 10^{-3}$ попадает в интервал $-4 \cdot 10^{-3} \leqslant(\Delta a / a)_{\perp} \leqslant+2 \cdot 10^{-3}$, установленный в работах $[4,5]$ по данным исследований ФЛ и ям травления для образцов GaInAsP/InP с высоким кристаллическим совершенством. Общее изменение содержания мышьяка на протяженности слоя GaInAsP для образца № 4 составило $\Delta y=0.01$, ФЛ данного образца была достаточно интенсивной и имела узкий спектр.

Для того чтобы рассчитать распределение $E^{\Gamma}$ по толщине эпитаксиального слоя $d$, мы полагали содержание индия $x$ по толщине слоя $\mathrm{Ga}_{1-x} \mathrm{In}_{x} \mathrm{As}_{y} \mathrm{P}_{1-y}$ постоянным, а для содержания мышьяка $y$ использовали аппроксимацию выражениями вида

$$
y_{a}(d)=y_{\infty}+\Delta y_{e} \exp \left[(d-h) / h_{d}\right]+k d,
$$

где $d$ - координата, отсчитываемая в глубь от поверхности структуры, $y_{\infty}, \Delta y_{e}, h_{d}, k-$ подгоночные параметры, $h$ - толщина эпитаксиального слоя GaInAsP, определенная методом ВИМС. Расчеты значений $E^{\Gamma}$ по толщине эпитаксиального слоя GaInAsP были выполнены с использованием параметров из работы [6], влияние деформаций не учитывалось, поскольку степень деформации оценить проблематично. Результаты расчетов для образцов № 3 и 4 представлены на рис. 2. Для образца № 3, согласно расчетам, значение $E^{\Gamma}$ минимально у поверхности и возрастает в глубь слоя GaInAsP, в то время как для образца № 4 имеется провисание $E^{\Gamma}$ в середине слоя GaInAsP. Известно, что между твердыми растворами GaInAsP различного состава, изопериодичными с InP, образуются гетеропереходы первого типа. Это значит, что при увеличении величины $E^{\Gamma}$ от поверхности в глубину слоя GaInAsP для образца № 3 у поверхности нет барьера для электронов и дырок и не создается эффекта широкозонного окна. У образца № 4 при уменьшении $E^{\Gamma}$ в глубину слоя образуется потенциальная яма для обоих типов носителей заряда, что подтверждается нашими расчетами по модели, изложенной в [7], т.е., согласно расчетам, на поверхности образца № 4 создается широкозонное окно, и этим мы объясняем достаточно высокую интенсивность ФЛ этого образца при 77 и $300 \mathrm{~K}$, а достаточно малую полную ширину на полувысоте от максимума $\Delta h v$ можно связать с малым значением градиента состава $\Delta y=0.01$. При этом и вариации величины $E^{\Gamma}$ по толщине эпитаксиального слоя у образца № 4 не столь велики, как у образца № 3. При $300 \mathrm{~K}$ образец № 3 имеет крайне низкую интенсивность ФЛ и также большую $\Delta h v$, что можно связать с большим градиентом состава и отсутствием эффекта широкозонного окна.

Таким образом, для слоев GaInAsP с удовлетворительным кристаллическим совершенством прослеживается связь между шириной $\Delta h v$ пиков ФЛ и градиентом состава по толщине.

\section{Благодарности}

Авторы выражают глубокую благодарность своим коллегам из ФТИ им. А.Ф. Иоффе: С.И. Трошкову за снимки сколов и поверхностей образцов, сделанные при помощи сканирующего электронного микроскопа (СЭМ); Б.В. Пушному за предоставление образцов для исследования.

\section{Финансирование работы}

Исследования ВИМС, СЭМ и „Саmebax“ проводились с использованием оборудования ЦКП „Материаловедение и диагностика в передовых технологиях“ (ФТИ им. А.Ф. Иоффе), поддерживаемого Минобрнауки (уникальный идентификатор проекта RFMEFI62117X0018).

\section{Конфликт интересов}

Авторы заявляют, что у них нет конфликта интересов. 


\section{Список литературы}

[1] Sasaki A. // Jpn. J. Appl. Phys. 1979. V. 19. N 9. P. 1695-1702.

[2] Васильев В.И., Гагис Г.С., Левин Р.В., Маричев А.Е., Пушный Б.В., Щеглов М.П., Кучинский В.И., Бер Б.Я., Казанцев Д.Ю., Горохов А.Н., Попова Т.Б. // Письма в ЖТФ. 2018. Т. 44. B. 24. C. 17-24.

[3] Marichev A.E., Levin R.V., Pushnyii B.V., Gagis G.S., Vasil'ev V.I., Scheglov M.P., Kazantsev D.Yu., Ber B.Ya., Popova T.B., Marukhina E.P. // J. Phys.: Conf. Ser. 2018. V. 1135. P. 012076 (1-5).

[4] Nakajima K., Yamazaki S., Komiya S., Akita K. // J. Appl. Phys. 1981. V. 52. N 7. P. 4575-4582.

[5] Mircea A., Mellet R., Rose B., Robein D., Thibierge H., Leroux G., Daste P., Godefroy S., Ossart P., Pougnet A-M. // J. Electron. Mater. 1986. V. 15. N 4. P. 205-213.

[6] Vurgaftman I., Meyer J.R., Ram-Mohan L.R. // J. Appl. Phys. 2001. V. 89. N 11. P. 5815-5875.

[7] Krijn M.P.C.M. // Semicond. Sci. Technol. 1991. V. 6. N 1. P. 27-31. 